\title{
Assessment of the Implications of GST (Goods and Services Tax) Rollout on Indian MSMEs
}

\author{
Vidit Mohan, Salman Ali \\ Indian Institute of Management Raipur, Raipur, India \\ Email: 17pgp160@iimraipur.ac.in, salman.ali@iimraipur.ac.in
}

How to cite this paper: Mohan, V. and Ali, S. (2018) Assessment of the Implications of GST (Goods and Services Tax) Rollout on Indian MSMEs. Theoretical Economics Letters, 8, 3567-3580. https://doi.org/10.4236/tel.2018.815219

Received: November 7, 2018

Accepted: December 8, 2018

Published: December 11, 2018

Copyright $\odot 2018$ by authors and Scientific Research Publishing Inc. This work is licensed under the Creative Commons Attribution International License (CC BY 4.0).

http://creativecommons.org/licenses/by/4.0/

\begin{abstract}
The purpose of this study is to understand the implications of the recent rollout (July 2017) of GST (Goods and Services Tax) in India on the MSME (Micro, Small, and Medium Enterprises) sector. The study comprises a series of qualitative face-to-face interviews which were followed up by a survey with Indian MSME owners. The study provides a multi-dimensional understanding of the gaps between the effect of the anticipated and existing GST regime for the MSMEs and the associated tax compliance. It identifies and assesses the inter-jurisdictional and other issues that are involved in GST implementation. There is scope to probe the means to enable the effective deployment of GST based on the findings of this study. The findings can also be used to develop guidelines for suitable implementation of the GST regime for the MSMEs operating in different sectors.
\end{abstract}

\section{Keywords}

GST (Goods and Services Tax), MSME (Micro, Small and Medium Enterprises), India, Implementation Challenges, Awareness, Profitability

\section{Introduction}

MSME (Micro, Small, and Medium Enterprises) sector in India always played a vital role in the economic development of the country via their contribution to the manufacturing output, provision of employment opportunities, promoting balanced economic development, increasing foreign exchange earnings, and exports. As on 2018, about 80 million employment opportunities are being generated by 36 million MSMEs, contributing to about 8\% of the GDP (Gross domestic product) and $33 \%$ of total manufacturing output in India [1]. Nonetheless, Indian MSMEs are undergoing an extremely dynamic and multi-faceted business scenario [2] [3]. The increasing influx of imports from neighboring China 
has significantly impacted several players in the MSME sector, and firms are under immense pressure to respond on cost efficiencies, quality parameters, and technology upgradation [4]. It is at this juncture that the union government has recently rolled out the GST (Goods \& Services Tax) across India replacing several existing taxes.

GST, or different variants of the same, had been implemented across the world in about 160 countries [5] and the small and medium enterprises had faced several challenges. Scholars have attempted to understand the compliance challenges faced by small and medium enterprises in countries such as Malaysia [6] and New Zealand [7], some of them such as in Australia [8] have contested the benefits realized by small businesses, while some others such as in Canada [9] have even debated on where to draw the line for small enterprises. However, as each country has its own unique characteristics, especially for the way of doing business for small and medium enterprises, we've attempted to focus our study specific to the Indian context.

GST has been viewed as a revolutionary reform of the taxation system in India [10] [11]. GST should not simply be realized as a new regime of taxation for businesses in India. Rather, it is aimed to be one of the prominent factors in defining and altering the way business is conducted in India [12] [13]. Several characteristics of the GST warrant attention if the MSMEs were to comply with the GST and to realize its intended benefits [14] [15]. The introduction of GST would influence the internal business processes of an organization as well as its functioning in the Indian market. Its compliance by the MSMEs necessitates a restructuring of the infrastructure and resources, in terms of the information technology systems, value chain, pricing, etc. [16]. The clarity on the key provisions of the GST can enable MSMEs to expand and compete beyond their local markets [17].

This paper is structured as follows. Firstly, we summarize the important characteristics of the Indian GST structure. We then describe the dual methods of data collection used in this study to understand the implications of GST implementation on Indian MSME sector, i.e. both the face-to-face qualitative interviews as well as a survey with Indian MSME owners as primary respondents.

The findings from the interviews illustrate the major pitfalls and anxiety on the GST implementation and its effect on MSMEs. Major findings from the survey indicate that: there is a need for enhanced Government commitment in the form of arranging the requisite training programs to improve the GST awareness among the MSMEs owners, increased GST awareness among MSMEs may lead to an increase in their financial and operational profitability, and enhanced Government commitment and increased awareness among the MSME owners would help standardize the work methods of the MSMEs.

This study bears implications for research, practice, and policy. Being among the first studies on the topic, it sets a foundation for researchers to frame, revise, and test related and new queries. From a practitioners' perspective, the findings that GST awareness can lead to better profitability should motivate MSMEs to 
make adequate investments in training and awareness activities. The study bears suggestive implications for policy-makers on how and where to support MSMEs on the GST sphere as it points out not just the challenges faced by MSMEs, but also the role and importance of training provided by government agencies to MSMEs, so as to bring them into the mainstream market.

\section{Characteristics of GST in India}

The GST is a comprehensive and destination-based consumption tax levied at multiple stages of value addition in the supply chain of the products and services. It came into effect from 1st July 2017 and aims to enforce a unified taxation system in the country. The two key advantages associated with GST are the reduction in the cascading effect of taxes and the plausible reduction in taxes through the provision of input tax credit [18]. The erstwhile cascading taxation scenario leads to a sequential increase in the price of a commodity due to the payment of tax on tax at each stage of product life cycle. GST also helps in regulating the E-commerce and unorganized sector. It is intended to reduce compliances issues, and also to provide ease in filing taxes. The major advantages of GST [19] are listed below:

- Elimination of the cascading effect of taxes

- Provision of composition levy for the MSMEs

- Regulation of the e-commerce and unorganized sector

- Reductions in compliance issues

- Ease of filing of tax returns

The major constituents of GST are described underneath. These concepts are aimed at inducing more competition in the export industry, together with the provision of protecting the domestic goods industry [20].

Time, Place and Value of Supply: There are provisions specified in GST regarding the "point of taxation" for the realization of the tax-rate, value, and time of payment of the taxes. There are different clauses for the supply of goods and rendering of services. The time of supply is taken to be earlier of the date of the issue of invoice and the date on which the payment is actually received [21]. There is also a clause for the time of supply under "reverse charge". The place of supply enables the determination of the chargeability of the tax in terms of State-GST (SGST), Central-GST (CGST) and Integrated-GST (IGST)/Dual GST. The tax is leveraged based on the location of the supplier and the corresponding place of supply.

Table 1 and Table 2 depict the tax structure and models under the GST regime [18].

The GST will be charged on the "transaction value" or the actual price paid or payable for the goods or services. This includes all charges or cost incurred until the managerial control is completely transferred. The discounts given prior to or at the time of supply, however, will be deducted from the transaction value. In case of a transaction between related entities, the value of supply would be either the open market value (OMV) or determined through residual or cost value 
Table 1. Tax structure under the GST regime.

\begin{tabular}{ccc}
\hline Type of Transaction & Tax Leveraged & Distribution of Tax \\
\hline Intra-State Supply & CGST + SGST & $\begin{array}{c}\text { Equal revenue sharing between state } \\
\text { \& central government }\end{array}$ \\
Inter-State Supply & IGST & $\begin{array}{c}\text { Revenue is distributed } \\
\text { based on the destination of goods }\end{array}$ \\
\hline
\end{tabular}

Table 2. GST model under the GST regime.

\begin{tabular}{ccc}
\hline Type & Levied by central government & Levied by state government \\
\hline Central GST & Yes & No \\
State GST & No & Yes \\
Dual GST & Yes & Yes \\
\hline
\end{tabular}

method for items of similar nature [22]. There are different provisions for determination, such as valuation based on $110 \%$ of the cost of manufacturing or provision of supply, number of man-hours required, etc. There are however different guidelines for businesses involved in the exchange of foreign currencies, air travel, and life-insurance business.

Composition Levy: The composition scheme mandates the tax return filing on a quarterly basis, instead of the business compliance pertaining to three monthly returns. This is primarily due to the limited resources and expertise available to MSMEs and start-ups with aggregate turnover below 7.5 million Indian Rupees [23]. This is, however, applicable only for the manufacturing sector as the service sector is excluded from this provision. The composition scheme allows for high liquidity, limited tax liability, and limited compliance [24]. There are lower tax rate slabs available under the scheme and detailed recordkeeping is not required for such businesses. The composition businesses, however, cannot avail input tax credit of GST and inter-state transactions are not permitted [25].

Input Tax Credit (ITC) and Reverse Charge: The provision of ITC is one of the fundamental features of GST and is concerned with the adjustment of tax on purchase against the liability of tax on the output [26]. ITC could be claimed only for purchases pertaining for the purpose of business and not for personal use. ITC is not allowed if the depreciation has been claimed on the capital goods for tax purpose. The reverse charge mechanism is concerned with the reversal of the tax payment liability from the supplier to the buyer [27]. It is aimed at increasing tax revenues and compliance by the inclusion of the unorganized sector. It is applicable to both services as well as manufacturing sectors. The compensation cess and ITC are applicable for the taxes paid on the reverse charge.

\section{Methodology and Findings}

As outlined earlier, our primary agenda was to understand how the recent rollout of the GST has affected the Indian MSME sector. In order to have a better understanding of the problem, we started with semi-structured open-ended 
interviews with MSME owners. These interviews were recorded and transcribed to capture the responses of the participants. Finally, a survey questionnaire was designed after consultation with business owners and chartered accountants.

\subsection{Qualitative Interviews}

We initially conducted a series of comprehensive, face-to-face, semi-structured interviews with the MSME operators/owners based at Raipur, India. The aim of this exercise was to understand and gain access to the way in which the owners attribute the meaning to the implementation of the GST and their perception to it. We were also interested in capturing the tax practices, decisions, perceptions, attitudes, and experiences of GST on a broad level. The set of questions we asked revolved around the following themes:

- Impact of the composition levy

- Tax compliance behavior

- Satisfaction/acceptance level

- Effect on profitability or profit margins

- Other issues, such as registration process, technical aspects, etc.

- Role of government institutes (MSME Development Institute in particular) in facilitating the GST implementation

Findings from Qualitative Interviews

The respondents' perceptions and experiences with GST were captured through qualitative interviews amongst two dozen MSME owners.

"Tax reform was needed", explained one interviewee, "GST is good for India and it's time to restructure the taxation system."

One of the respondents supported these views by noting: "It is one of the best tax systems since years and the small businesses will definitely benefit from it in the long term."

The owner of a software services firm described his insistence on the change, "GST appears reasonable and I support this tax reform. We will adapt to GST with time."

In the words of another respondent, "GST is good theoretically. However, I am critical of the manner in which GST has been implemented."

Another respondent of a small-sized firm believed that: "Making a departure from the traditional tax system is tough for our company due to the lack of guidance and knowledge."

One of the respondents from a manufacturing firm recalled, "GST is the worst tax system since years and is unreasonably complicated, given the limited resources in terms of time and capital available with the MSMEs.”

To summarize, some of the major challenges mentioned by MSMEs owners (recurring comments) and charted accountants in the adoption of GST were:

- Too costly in terms of time and money; High compliance cost because of high staff time and recordkeeping requirements.

- GST system is complex and will lead to shutting down of many small busi- 
nesses.

- GST has eroded profitability margins.

- GST filing server is usually not functional on the 8th or 9th of each month (Deadline on 10th), leading to penalties on a frequent basis. Extension of return filing dates and slab rate changes are required.

- MSMEs were called for training and knowledge sharing sessions before implementation of GST only; Only a few seminars were organized post GST rollout.

- Detailed online stepwise procedure for GST filing is not available.

- Connectivity issues, particularly in rural areas. There should be some offline facility for return filing (particularly in areas facing connectivity issues/remote areas).

- No changes allowed once the returns/invoice details are submitted/filed.

- No feedback mechanism in place. No response received by MSMEs in case of any issue or inquiry.

- Penalty imposed on clients even after receiving the confirmation message on completion of filing.

- No clarity on input tax credit is available.

- Composition levy good for only small retailers; For large businesses, it leads to no reverse benefit.

\subsection{Quantitative Survey}

A structured paper-based questionnaire was used to collect data from MSME owners in Raipur, India. The questionnaire had close-ended questions where respondents were asked to choose one among the following five-point Likert type scale options.

1) Strongly disagree.

2) Disagree.

3) Neither agree nor disagree.

4) Agree.

5) Strongly agree.

The questionnaire was tested through correlation analysis before application. This was essential to ensure that the participants understand and interpret it in the manner that we expected. It was also crucial to yield useful data. 47 of the 71 firms who were given the questionnaire responded to the survey, i.e. about $66 \%$ response rate.

\subsubsection{Research Hypotheses for Quantitative Survey}

One of the prominent issues with the compliance of GST for the MSMEs is a lack of awareness and knowledge about its constituents. Though training programs were arranged for the effective roll-out of this new tax regime, the interviews showed that a significant gap between formulation and implementation remained on the surface. The MSME owners were quite apprehensive about the various norms of GST and this has contributed significantly towards their dissa- 
tisfaction with GST [28]. The increased burden of tax filing has affected the operations of many MSMEs. From the interviews, it was clear that many MSMEs experienced a contraction in their business and a substantial effect on their profitability margins. The implementation of GST has severely eroded their profit margins at an increasing trend.

The need to maintain proper documentation has contributed to the increased work-load and thereby to compliance costs for the MSMEs [29]. Quite often, the documentation cost serves as a major contributor to their administrative costs. This also possibly necessitates a need for the development of an integrated communication channel across the value chain [30]. Some of the features could only prove to be useful for the MSMEs if only there was an integration of the entire value chain in the GST regime [31].

Firms' ability to adapt to GST and reconfigure their resources requires an understanding of the business-specific needs. MSMEs need to be well-equipped for a smooth implementation process of GST and should understand the tax impact on their core operations. The development of an integrated approach to assess and implement GST, and gauging the anticipated effects is a necessary condition in the present business environment which is characterized by a lack of GST awareness and training. This necessitates the provision of the guidance regarding the requisite procedure to address the challenges and determine the opportunities in the post-GST era. We, therefore, anticipated that the provision of training programs by the government would be a key facilitator to enhance GST awareness among the MSMEs.

Training would facilitate the MSMEs to gain insights about the effect of GST on the different business functions and operations. This increased awareness would allow them to reconfigure their resources to exploit the opportunities post GST roll-out. This would translate in terms of higher profitability and better synchronization across the value chain. The impact could be characterized in terms of operating income, expenses, profit margins, and working capital requirements.

Hence, we state the following set of hypotheses for testing:

H1: Government commitment along with requisite training programs would enhance the GST awareness among the MSMEs.

H1.1: Government commitment along with requisite training programs would enhance the satisfaction level among the MSMEs

H1.2: Government commitment along with requisite training programs would enhance the utility for the MSMEs

H2: GST awareness among MSMEs would have a positive impact on their profitability.

H2.1: GST awareness would have a positive impact on the financial profitability of the MSMEs

H2.2: GST awareness would have a positive impact on the operational profitability of the MSMEs 
Training programs would also encapsulate the provisions about the documentation requirements for filing the returns and other key data required to comply with GST. The training workshops and seminars would enable the MSME owners to understand GST and to tackle key issues. They may thereby examine and validate their business processes and functions towards a comprehensive transition to GST. Post GST roll-out, the MSMEs are required to recalibrate and validate their operating model to ensure a smooth functioning of their business. The robust understanding or awareness about the impact on their value chain elements and operations would allow them to capture the intended value on account of GST implementation. MSMEs would be able to better quantify the effect on the fiscal, technical and the value chain fronts through proper training and awareness.

Further, the GST requires the businesses to maintain certain records. In accordance with the documentation requirements, the MSMEs may undertake activities to ensure coordination amongst its various work streams and vendors. The communication across the value chain would improve through the identification of key issues, their plausible impact on business functions and development of a mitigation plan among the various stakeholders.

Hence, we state the final set of hypotheses as follows:

H3: Government commitment together with requisite training programs and awareness would have a positive impact on the work methods of the MSMEs.

H3.1: Government commitment together with requisite training programs and awareness would have a positive impact on the firm level documentation H3.2: Government commitment together with requisite training programs and awareness would have a positive impact on the communication across the value chain

\subsubsection{Findings from Quantitative Survey}

Following are the major findings from the survey administered amongst the MSME owners.

\section{H1. Government commitment, Training programs, and GST Awareness}

The two variables of GST awareness-satisfaction level and utility-are considered as dependent variables and dimensions of the Government commitment and the GST training programs are considered as the independent variables. The results of the regression analysis for the satisfaction level of the MSMEs are presented in Table 3. Large values of $\mathrm{R}$ indicate a strong relationship. Table 4 summarizes the results of the analysis of the variance for the satisfaction level.

The results show a strong and positive linear correlation between government commitment, training programs, and GST satisfaction level. It implies that an increase in the government commitment and training programs would lead to an increase in the satisfaction of the MSMEs owners with the GST. Hence, the results support hypothesis H1.1.

The results of the regression analysis for the utility for the MSMEs are presented in Table 5 and Table 6. 
The results show a strong and positive linear correlation between government commitment, training programs and utility for the MSMEs. It implies that an increase in the government commitment and training programs would lead to an increase in the utility. Hence, the results support hypothesis H1.2.

Hence, the results prove hypothesis $\mathrm{H} 1$.

This indicated that there is a need to provide training to reduce compliance efforts through detailed awareness about the methods of input tax credit claim, the regulation and filing process, the mechanism of reverse charges and other aspects of the structure of the GST regime.

\section{H2. GST awareness and Profitability of MSMEs}

The two variables of profitability-financial and operational productivity-are considered as dependent variables and dimensions of the GST awareness are considered as the independent variables. Tables 7-10 summarize the results of the analysis.

The results from Table 7 and Table 8 show a strong and positive linear correlation between GST awareness on the financial productivity of the MSMEs. Hence, the results support the hypothesis $\mathrm{H} 2.1$.

The results from Table 9 and Table 10 show a strong and positive linear correlation between GST awareness on the operational productivity of the MSMEs. Hence, the results support the hypothesis $\mathrm{H} 2.2$.

Hence, the results prove hypothesis $\mathrm{H} 2$.

Thus, GST awareness was found to influence profitability of MSMEs. There is scope to formulate the means to reduce the tax compliance burden on the MSMEs. This would directly translate to the lowering of administration costs, thereby improving their profitability.

\section{H3. GST Awareness and Work Methods of MSMEs}

The two variables of work methods-documentation and communicationare considered as dependent variables and dimensions of the government commitment together with requisite training programs and awareness are considered as the independent variables. Tables 11-14 summarize the results of the analysis.

The results from Table 11 and Table 12 show a strong and positive linear correlation between documentation and the government commitment together

Table 3. Model-GST satisfaction.

\begin{tabular}{ccc}
\hline Model & R & R square \\
\hline Government Commitment (Constant) & 0.815 & 0.664 \\
Training Program (Constant) & 0.815 & 0.664 \\
\hline
\end{tabular}

Table 4. Analysis of variance-GST satisfaction.

\begin{tabular}{ccccc}
\hline Analysis of variance & Sum of squares & Mean square & F & Sig. \\
\hline Regression & 10.654 & 1.64 & 10.78 & 0.0 \\
Residual & 5.77 & 0.173 & & \\
Total & 16.424 & & & \\
\hline
\end{tabular}


Table 5. Model-GST utility.

\begin{tabular}{ccc}
\hline Model & R & R square \\
\hline Government Commitment (Constant) & 0.742 & 0.551 \\
Training Program (Constant) & 0.742 & 0.551 \\
\hline
\end{tabular}

Table 6. Analysis of variance-GST utility.

\begin{tabular}{ccccc}
\hline Analysis of variance & Sum of squares & Mean square & F & Sig. \\
\hline Regression & 13.942 & 2.457 & 7.68 & 0.0 \\
Residual & 10.432 & 0.279 & & \\
Total & 24.374 & & & \\
\hline
\end{tabular}

Table 7. Model-Financial productivity.

\begin{tabular}{ccc}
\hline Model & R & R square \\
\hline GST Awareness & 0.812 & 0.659 \\
\hline
\end{tabular}

Table 8. Analysis of variance-Financial productivity.

\begin{tabular}{ccccc}
\hline Analysis of variance & Sum of squares & Mean square & F & Sig. \\
\hline Regression & 13.612 & 4.871 & 31.442 & 0.0 \\
Residual & 5.331 & 0.143 & & \\
Total & 18.943 & & & \\
\hline
\end{tabular}

Table 9. Model-Operational productivity.

\begin{tabular}{ccc}
\hline Model & $\mathbf{R}$ & R square \\
\hline GST Awareness & 0.789 & 0.623 \\
\hline
\end{tabular}

Table 10. Analysis of variance-Operational productivity.

\begin{tabular}{ccccc}
\hline Analysis of variance & Sum of squares & Mean square & F & Sig. \\
\hline Regression & 11.589 & 3.747 & 25.233 & 0.0 \\
Residual & 5.312 & 0.134 & & \\
Total & 16.901 & & & \\
\hline
\end{tabular}

Table 11. Model-Documentation.

\begin{tabular}{ccc}
\hline Model & R & R square \\
\hline Government Commitment (Constant) & 0.757 & 0.573 \\
Training Program (Constant) & 0.757 & 0.573 \\
GST Awareness (Constant) & 0.757 & 0.573
\end{tabular}

Table 12. Analysis of variance-Documentation.

\begin{tabular}{ccccc}
\hline Analysis of variance & Sum of squares & Mean square & F & Sig. \\
\hline Regression & 22.106 & 2.903 & 8.312 & 0.0 \\
Residual & 11.212 & 0.232 & & \\
Total & 33.318 & & & \\
\hline
\end{tabular}


Table 13. Model-Communication.

\begin{tabular}{ccc}
\hline Model & R & R square \\
\hline Government Commitment (Constant) & 0.832 & 0.692 \\
Training Program (Constant) & 0.832 & 0.692 \\
GST Awareness (Constant) & 0.832 & 0.692 \\
\hline
\end{tabular}

Table 14. Analysis of variance-GST utility.

\begin{tabular}{ccccc}
\hline Analysis of variance & Sum of squares & Mean square & F & Sig. \\
\hline Regression & 24.376 & 2.943 & 10.312 & 0.0 \\
Residual & 8.743 & 0.432 & & \\
Total & 33.318 & & \\
\hline
\end{tabular}

with requisite training programs and awareness. Hence, the results support the hypothesis H3.1.

The results from Table 13 and Table 14 show a strong and positive linear correlation between communication and the government commitment together with requisite training programs and awareness. Hence, the results support the hypothesis H3.2.

Hence, the results prove hypothesis $\mathrm{H} 3$.

It is thus evident that the increase in training and awareness for the MSMEs would allow them to have a more disciplined approach in their day-to-day operations as well as the business as a whole. The increased transparency would thus allow the MSMEs to obtain credit at the competitive market rates [32].

To summarize, the regression and variance analysis indicated the following broad themes:

- There is a need of enhanced government commitment in the form of arranging the requisite training programs to improve the GST awareness among the MSMEs owners. This is highly convenient for the owners to gain a proper understanding of the GST and thereby enhancing their compliance with the GST.

- The increased GST awareness among MSMEs may lead to an increase in their financial and operational profitability. The enhanced government commitment in the form of arranging the requisite training programs may indirectly translate to a higher profit-gaining ability for the MSMEs.

- The enhanced government commitment and increased awareness among the MSME owners would help standardize the work methods of the MSMEs. The need of record-keeping mandated under GST would thus help improve the work methods, particularly related to tax-filing and business conduct across the various elements of the value chain.

\subsection{Summary of Findings from Both Studies}

The major findings from both qualitative interviews and the quantitative survey 
can be summarized as below:

- MSMEs face several challenges during GST implementation.

- Many enterprises find the GST to be very complex and costly to implement and for some it significantly affects their profit margins.

- There are several operational issues related to the GST filing website, connectivity issues in rural areas, and lack of feedback mechanism.

- MSMEs are eagerly looking forward to government training and awareness programs, which can help their financial and operational profitability while implementing GST.

\section{Conclusions}

In this study, we comprehensively assessed the implications of the recent introduction of GST on Indian MSMEs using both qualitative interviews and a survey.

The detailed face-to-face semi-structured interviews helped us to identify the real issues and challenges faced by MSME owners over the adoption of GST. It also pointed out various deficiencies in the system that especially warrants institutional attention. The questionnaire survey that followed indicated the need for government initiatives and training on GST awareness for MSMEs and its subsequent impact on their profitability.

This being among the first comprehensive research on the subject, particularly in the Indian context, we expect our study to throw many insights to researchers, practitioners, as well as policymakers. Being an ongoing and contemporary phenomenon, some of these needs immediate attention and a few others could be bettered over time.

From a research perspective, our use of mixed methods of qualitative interviews followed by a quantitative survey is noteworthy and important while studying phenomena that are contemporary in nature to bring out many important findings. We hope this study would set as a foundation of future research on the topic and may help scholars to dig into deeper and revised queries.

The findings of our study have implications for MSME owners. Firstly, they can have a better understanding of common issues faced by their contemporaries, which may help them to be better prepared for certain situations. The findings also show a positive relationship between awareness of GST structure and profitability of firms, which should motivate MSME owners to invest time and effort to understand the GST structure not just for compliance but for better returns to their ventures.

The findings of our study also pinpoint many structural deficiencies and operational issues over GST implementation which needs attention at an institutional level. Further, policymakers may also want to specifically make note the need and importance of training and awareness activities for MSME owners to bring them into the GST main-stream taxation, which, in turn, can lead to better compliance and enhanced tax revenues to the state. 


\section{Acknowledgements}

The authors would like to thank for and acknowledge the support extended by MSME Development Institute, Raipur for their assistance to reach out to MSME owners at Raipur India. Also, the assistance provided by Shakti Mishra and Vinay Jain, IIM Raipur, during the data collection process is highly appreciated.

\section{Conflicts of Interest}

The authors declare no conflicts of interest regarding the publication of this paper.

\section{References}

[1] Ministry of Micro, Small and Medium Enterprises (2018) MSME Annual Report 2017-18. Government of India, New Delhi.

[2] Jena, N.R. and Thatte, L.R. (2008) Performance of the Micro, Small And Medium Enterprises (MSMEs) Manufacturing Sector in Select States in India: The Concept of MSME Manufacturing Business Facilitator (MSME-MBF) Index. Academy of Entrepreneurship Journal, 24, 1-22.

[3] Suresh, P. and Mohideen, M.A. (2012) Small and Medium Enterprises in IndiaIssues and Prospects. International Journal of Management Research and Review, 2, 247-255.

[4] Bhatt, N. (2016) Modelling of the Factors Influencing the Implementation of Advance Manufacturing Technologies in MSME. Global Journal of Enterprise Information System, 8, 12-26. https://doi.org/10.18311/gjeis/2016/15652

[5] Countries Implementing GST or VAT. 2014. http://gst.customs.gov.my/en/gst/Pages/gst_ci.aspx

[6] Ramli, R., Palil, M.R., Hassan, N.S.A. and Mustapha, A.F. (2015) Compliance Costs of Goods and Services Tax (GST) among Small and Medium Enterprises. Journal Pengurusan, 45, 39-48.

[7] Buchan, H., Olesen, K., Black, A. and Kumar, R. (2012) Compliance Costs: The Impact of the Increased GST Rate on Two New Zealand Businesses. New Zealand Journal of Applied Business Research, 10, 49-67.

[8] Isle, M.B., Freudenberg, B. and Copp, R. (2014) Cash Flow Benefit from GST: Is It Realised by Small Businesses in Australia? Australian Tax Forum, 29, 417-454.

[9] Zu, Y. (2018) VAT/GST Thresholds and Small Businesses: Where to Draw the Line? Canadian Tax Journal, 66, 309-347.

[10] Nilanjan, K. and Nidhi, S. (2018) Relevance of GST HSN Codes for Indirect Tax Implementation in India: A Review. BULMIM Journal of Management and Research, 3, 39-45. https://doi.org/10.5958/2455-3298.2018.00006.5

[11] Sehrawat, M. and Dhanda, U. (2015) GST in India: A Key Tax Reform. International Journal of Research-Granthaalayah, 3, 133-141.

[12] Kumar, N. (2014) Goods and Services Tax in India: A Way Forward. Global Journal of Multidisciplinary Studies, 3, 216-225.

[13] Sharma, R. (2017) Impact of Goods and Service Tax (GST) on Economy of India-A Review. International Journal of Engineering Technology Science and Research, 4, 559-561.

[14] Rai, V.K. (2018) Consequences of GST for Micro, Small and Medium Enterprises. 
In: GST Simplified Tax System: Challenges and Remedies, Swaranajali Publication, Delhi, 296-299.

[15] Turka, S.K. and Singh, S.G. (2017) Impact of Goods and Service Tax (GST) on Micro, Small and Medium Enterprises (MSMEs). Academic Disclosure, 6, 89-93.

[16] Chaturvedi, V.K. (2018) GST and Small Scale Industries: An Critical Analysis. GST Simplified Tax System: Challenges and Remedies.

[17] Srinivas, K.T. (2013) Role of Micro, Small and Medium Enterprises in Inclusive Growth. International Journal of Engineering and Management Research, 3, 57-61.

[18] Council, G.S.T. (2018) GST Knowledge Overview. http://gstcouncil.gov.in/sites/default/files/01092018_GST_PPT_An_Update.pdf

[19] Praharaj, A. (2017) GST-Advantages \& Disadvantages for Startups and Tiny Businesses in India. International Journal of Commerce, Business and Management, 1 , 30-39.

[20] Rametse, N. and Pope, J. (2002) Start-Up Tax Compliance Costs of the GST: Empirical Evidence from Western Australian Small Businesses. Australian Tax Forum, 17, 407-442.

[21] Nath, B. (2017) Goods and Services Tax: A Milestone in Indian Economy. International Journal of Applied Research, 3, 699-702.

[22] Pope, J. and Rametse, N. (2001) Small Business and the Goods and Services Tax: Compliance Cost Issues Small Enterprise Research. Journal of SEAANZ, 9, 42-54.

[23] Rao, V.J.K., Satyanaseryanachery, T. and Shyamsundar, C. (2009) State of Small and Medium Enterprises in India. The Management Accountant, 44, 264-267.

[24] Dutta, S. (2002) Urbanization and Development of Rural Small Enterprises: Study the Linkage with Focus on West Bengal. Economic and Political Weekly, 37, 3181-3189.

[25] Thompson, J. and Lumpkin, S. (2004) The SME Financing Gap: Theory and Evidence. Organisation for Economic Co-Operation and Development, 1, 11-17.

[26] Zainal, R., Teng, T. and Mohamed, S. (2006) Construction Costs and Housing Prices: Impact of Goods and Services Tax. International Journal of Economics and Financial Issues, 6, 16-20.

[27] Schuetze, H.J. and Bruce, D. (2004) Tax Policy and Entrepreneurship. Swedish Economic Policy Review, 11, 233-265.

[28] Wagner, J. (1994) The Post-Entry Performance of New Small Firms in German Manufacturing Industries. Journal of Industrial Economics, 42, 141-154. https://doi.org/10.2307/2950486

[29] Yong, S. (2006) A Critical Evaluation of the Economic Deterrence Model on Tax Compliance. New Zealand Journal of Taxation Law and Policy, 12, 95-116.

[30] Suhartanto, D. and Leo, G. (2018) Small Business Entrepreneur Resistance of ICT Adoption: A Lesson from Indonesia. International Journal of Business and Globalisation, 21, 5-18. https://doi.org/10.1504/IJBG.2018.094092

[31] Directorate General of Taxpayer Services (2017). http://www.cbic.gov.in/resources//htdocs-cbec/gst/sectoral-booklets-msme.pdf;jsess ionid=71E65700AA883D055B4B1E5ECCE2106B

[32] Singh, R., Verma, O. and Anjum, B. (2012) Small Scale Industry: An Engine of Growth. Zenith International Journal of Business Economics \& Management Research, 2, 210-221. 